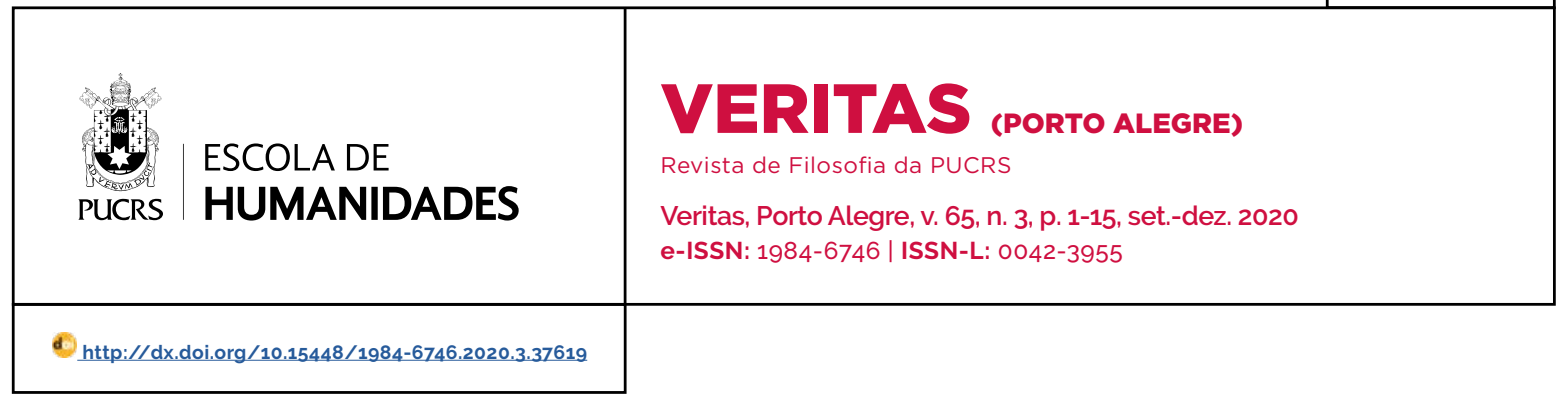

SEÇÃO EPISTEMOLOGIA E FILOSOFIA DA LINGUAGEM

\title{
A presença dos gregos na análise bergsoniana das ciências e da metafísica
}

\author{
The presence of the Greeks in the Bergsonian analysis of sciences and metaphysics \\ La presencia de los griegos en la análisis bergsoniana de la ciencia y de la metafísica
}

\author{
Tomás Prado ${ }^{1}$ \\ 0000-0002-7319-7102 \\ tomasmsprado@gmail.com
}

Recebido em: 8/4/2020.

Aprovado em: 4/9/2020

Publicado em: 12/01/2021.
Resumo: Em 1911, Henri Bergson proferiu na Universidade de Oxford conferências em que associa sua visão das ciências ao pensamento grego. Com base nessa comparação, trata-se de reconstituir sua análise das ciências e da metafísica desde os cursos que ele ofereceu na juventude sobre a filosofia grega. Consideramos que eles explicitam tanto seu vínculo com a tradição filosófica quanto a radicalidade do seu pensamento, sobretudo nas conclusões metafísicas de $A$ evolução criadora. Nesse percurso, pretendemos distinguir a física e a matemática da psicologia e da biologia; reconstituir as diferenças que ele identifica entre escolas gregas; cotejar postulados do pensamento antigo com os do pensamento moderno; e demonstrar com quais aspectos dessas referências a filosofia bergsoniana possui maiores afinidades. Não se trata de reduzir seu pensamento à filosofia dos antigos, mas demonstrar como essa interlocução é especialmente profícua em sua análise das ciências e da metafísica.

Palavras-chave: Mudança. Espaço. Percepção. Ciência. Metafísica.

Abstract: In Henri Bergson's lectures at Oxford University in 1911, the philosopher associates his sciences' view with Greek thought. Based on this comparison, it is a matter of reconstructing his analyses of sciences and metaphysics since the courses he offered in his youth on Greek philosophy. We consider that it explains its link with the philosophical tradition and the radicality of his thinking, especially in the metaphysical conclusions of The creative evolution. Along this path, we intent to distinguish physics and mathematics from psychology and biology; to reconstitute the differences that Bergson identifies between Greek schools; to compare postulates of ancient thought with those of modern thought; and to demonstrate which aspects of these references Bergsonian philosophy has the greatest affinities with. It is not a question of reducing his thinking to the philosophy of the ancients, but to show how this dialogue is especially important in his analysis of the sciences and metaphysics.

Keywords: Change. Space. Perception. Science. Metaphysics.

Resumen: En 1911, Henri Bergson dio conferencias en la Universidad de Oxford en las que asoció su visión de las ciencias con el pensamiento griego. Con base en esa comparación, se trata de reconstruir su análisis de las ciencias y de la metafísica desde los cursos que impartió en su juventud sobre filosofía griega. Consideramos que explican tanto su vinculación con la tradición filosófica como la radicalidad de su pensamiento, especialmente en las conclusiones metafísicas de La evolución creadora. En este recorrido, pretendemos distinguir la física y la matemática de la psicología y de la biologia; reconstituir las diferencias que identifica entre las escuelas griegas; cotejar los postulados del pensamiento antiguo con los del pensamiento moderno; y demostrar con qué aspectos de estas referencias la filosofía bergsoniana tiene mayores afinidades. No se trata de reducir su pensamiento a la filosofía de los antiguos, sino de mostrar cómo este diálogo es especialmente útil en su análisis de las ciencias y de la metafísica. Palabra clave: Cambio. Espacio. Percepción. Ciencia. Metafísica. 


\section{Introdução}

Em 1911, Henri Bergson proferiu na Universidade de Oxford duas palestras sob o título "A percepção da mudança". Aos 52 anos de idade, ele usufruía de notável reconhecimento pela publicação de quatro obras: Ensaio sobre os dados imediatos da consciência (1889), O riso Ensaio sobre a significação do cômico (1894), Matéria e memória (1896) e A evolução criadora (1907). $\mathrm{O}$ eixo que atravessa a sua produção pode ser identificado ao tema das palestras em Oxford, ou seja, a investigação da "mudança", e isto conduziu Bergson a travar um debate direto com as ciências e com a metafísica. As palestras oferecem tanto um resgate dessa trajetória, quanto uma importante indicação da presença que nela tiveram os antigos gregos. Pretendemos demonstrar que 0 debate com as ciências e com a metafísica está fortemente marcado por essa presença de um modo ainda subestimado, e que ela contribui para reforçar suas diferenças com a tradição, notadamente as filosofias de Aristóteles e Kant.

Além das palestras e livros mencionados, Bergson realizou muitas falas que foram posteriormente reunidas nos compêndios $A$ Energia espiritual (1919) e O pensamento e o movente (1934). Apesar de ter declarado em testamento que não autorizava a publicação póstuma de nada que ele não tivesse publicado em vida, Henri Hude organiza, nos anos 1990, um material inédito, e passamos a ter acesso aos cursos que Bergson ofereceu na juventude. Destacamos a publicação, em 2000, dos quatro cursos oferecidos durante os anos 1880 e 1890 sobre os antigos gregos.

O dilema relativo ao cumprimento ou não do desejo do filósofo talvez tenha contribuido para retardar o reconhecimento da importância dos gregos em seu pensamento, uma vez que por décadas esse material permaneceu quase ignorado. A principal exceção é a aproximação entre Bergson e Plotino proposta por Rose-Marie Rossé-Bastide em sua tese de 1959 Bergson et Plotin. Apesar dos méritos de sua análise, a autora se atém às relações entre Plotino, Platão e Aristóteles.

Com relação à edição dos textos, prevaleceu a ideia de Gouhier, expressa no prefácio de Aulas de psicologia e metafisica, e com a qual concordamos, de que as contribuições de um grande filósofo para a história do pensamento possuem maior relevância do que suas motivações pessoais e que isso justifica a edição do material. Vamos além e sugerimos que a análise da sua produção pode contrariar avaliações gerais que o filósofo apresentou da própria obra. Devemos privilegiar a autonomia das produções em detrimento das retrospectivas apresentadas.

Impressiona o quanto a relação entre Bergson e os gregos ainda carece de atenção, de modo que, por exemplo, os prestigiados Annales bergsoniennes ainda não dedicaram nenhum volume ao tema. O fato surpreende, sobretudo, quando reconhecemos que a incursão na filosofia grega ocupa uma parte relevante na obra de outros grandes filósofos de nossa época, como Heidegger, Foucault e Arendt. Esses três filósofos dirigiram a Bergson críticas que podem ter marcado por décadas a recepção do seu pensamento, ${ }^{2}$ restando ao livro de Deleuze Bergsonismo, em 1966, realizar uma leitura mais simpática, embora também nele a aproximação com os gregos seja limitada, tendo como foco Platão.

No final dos anos 1990, destacadamente com o trabalho de Frédéric Worms, ${ }^{3}$ surge um amplo movimento de resgate da filosofia bergsoniana na França. No entanto, Worms segue a direção de Gouhier ao apontar Zenão como principal referência entre os antigos. Em geral, ele se dedica mais à posição de Bergson no "momento filosófico" dos anos 1900 e à interlocução com os modernos. No Brasil, a revitalização do bergsonismo ocorreu concomitantemente ou antecipadamente, com a dedicação de Bento Prado Junior (1989) e Franklin Leopoldo e Silva (1994) à sua filosofia, porém sem uma dedicação profunda à relação

\footnotetext{
Heidegger reduz, em Ser e tempo, a concepção de tempo de Bergson a de Aristóteles e censura as aproximações entre psicologia e filosofia assim como o primado da biologia. Arendt afirma em $A$ vida do espírito que Bergson foi o último filósofo a poder tratar da intuição, e Foucault assevera, em O nascimento da clínica, que Bergson promoveu "uma cavalgada louca para a imortalidade" (FOUCAULT, 2011, p. 189). 3 Ver WORMS, F. Introduction a Matière e mémoire (1997), Le vocabulaire de Bergson (2000) e Bergson ou les deux sens de la vie (2004).
} 
do filósofo francês com os gregos. ${ }^{4}$

A falta de um cânone que trate dessa aproximação, em grande medida, se deve também ao fato de que, nas principais obras publicadas em vida, e principalmente em A evolução criadora, o tratamento que o filósofo dedica aos gregos principalmente a Zenão e Platão - é pejorativo. Bergson se utiliza dessas referências para estabelecer a origem do que considera equívocos filosóficos, demarcando seu distanciamento. Ao se referir ao pensamento grego sem fazer distinção entre as diferentes escolas, somos levados a pensar que o filósofo critica uma posição não apenas hegemônica, mas univoca.

Os cursos e palestras demonstram, por outro lado, que seu conhecimento dos gregos era mais abrangente e profundo do que o que foi expresso nas grandes obras; que as afinidades vão além de uma aproximação apressada com Heráclito, 5 que sua compreensão da modernidade passa por uma comparação com a filosofia grega; e, como pretendemos revelar, que Bergson reconhece, em outros gregos, ideias bastante próximas daquelas que ele próprio defende. Ele as expressou mesmo antes de publicar suas grandes obras.

A dedicação aos gregos, que começou na juventude dos anos 1880 e perdurou até ao menos os anos de 1900 a 1904, nos quais ocupou o cargo de Chaire de philosophie grecque e latine no Collège de France, também possui como importante referência a tese complementar $O$ que Aristóteles pensou sobre o lugar (1889) e as Aulas de psicologia e metafísica (1892-1893), que, neste estudo, comporão com "A percepção da mudança" e os Cursos sobre a filosofia grega a principal fonte para a investigação da presença dos antigos em sua compreensão das ciências e da metafísica.

\section{Uma disputa metafísica divide as ciências}

A presença dos gregos na compreensão de Bergson das ciências é explicitada nas palestras de 1911 sob o título "A percepção da mudança":

\begin{abstract}
Estudemos antes os antigos, impregnemo-nos de seu espírito e procuremos fazer, na medida de nossas forças, aquilo que eles próprios fariam caso estivessem entre nós. Iniciados na nossa ciência (não digo apenas na nossa matemática e na nossa física, que talvez não mudassem radicalmente seu modo de pensar. mas sobretudo na nossa biologia e na nossa psicologia), chegariam a resultados muito diferentes daqueles que obtiveram. É isso que me impressiona mais particularmente no que diz respeito ao problema que me propus a tratar diante de vocês, o da mudança (2006, p. 150).
\end{abstract}

Conduzidos ao cerne da sua investigação - àquilo que mais o impressiona no problema da mudança - somos também remetidos aos gregos, mas advertidos de que eles a pensaram diferentemente de nós, modernos. Para recolocar a percepção da mudança em um campo de estranhamento, Bergson propõe que nos impregnemos do espírito grego, mas que pensemos como eles não as suas ciências, e sim as nossas, de modo que essa analogia implica também um deslocamento epistemológico.

Agora avançaremos no discernimento de alguns aspectos do problema. Quais ciências são essas? Como elas se dividem entre os antigos e os modernos? E, afinal, a quais gregos Bergson se refere? A começar pela distinção entre as ciências, ele propõe que a física e a matemática modernas não levariam os gregos a resultados diferentes, porque essas ciências, em seus fundamentos, não mudaram significativamente desde então ${ }^{6}$. Todavia, quanto à compreensão da mudança, algo diferente ocorreria se os gregos tivessem feito psicologia e biologia, ou ao menos caso tivessem dado a elas a importância central da sua época.

Com isso, reunimos elementos importantes de sua compreensão dos gregos com significativas implicações epistemológicas: que a mudança não pode ser pensada da mesma forma pelas ciências física e matemática e pelas ciências psicologia e biologia; e que se trata de liberar, sob a perspectiva da mudança, a psicologia e a biologia do modelo estabelecido pela matemática

\footnotetext{
4 Ver PRADO JUNIOR, B. Presença e campo transcendental: consciência e negatividade na filosofia de Bergson; e LEOPOLDO E SILVA, F. Bergson - Intuição e discurso filosófico.

5 Henri Hude afirma a respeito da visão bergsoniana dos gregos que "sua capacidade de simpatia, admirável quando se trata dos estoicos, permanece fria diante dos pré-socráticos, salvo de Heráclito" (2005, p. XII).

6 Bergson não se refere à física de Einstein e Heisenberg, mas à fisica de Galileu e Newton.
} 
e pela fisica. Finalmente, inspirados pelas duas outras, poderiamos também liberar a "percepção da mudança" na filosofia do modelo oriundo da fisica e da matemática. De fato, essa é uma ideia já defendida, em 1907, no terceiro capítulo de $A$ evolução criadora:

A física compreende o seu papel ao impelir a matéria no sentido da espacialidade; mas a metafísica terá compreendido o seu, ao limitar-se a ir atrás da física, com a esperança quimérica de ir mais longe na mesma direção? A sua tarefa específica não seria, pelo contrário, voltar a subir a encosta que a física desce, fazer voltar a matéria à sua origem e constituir progressivamente uma cosmologia que fosse, se assim é lícito dizer, uma psicologia invertida? (2009, p. 230). ${ }^{7}$

Em vez de seguir o modelo da fisica e da matemática, que reduz a mudança a um esquema espacial, a metafisica deveria se ater à percepção da mudança, seguindo a direção oposta, da duração. Chegariamos, então, a um modelo cosmológico análogo àquele que a psicologia oferece de nossa consciência e que a biologia oferece da evolução dos seres vivos.

Quanto aos demais aspectos do problema, Bergson sabe que os gregos pensaram diferentemente a mudança, não pela biologia e pela psicologia, mas na própria física. Uma divisão na concepção dessa ciência entre eles fez com que uma primeira percepção da mudança fosse preterida por aquela que se impôs até a modernidade. Por sua vez, a filosofia viria a se assumir como um pensamento delimitado pelo horizonte aberto por essa concepção de física. Seja na forma do ceticismo moderado de Hume, ou da filosofia crítica, de Kant, a metafísica foi levada à crise por preceitos da física moderna, que circunscrevem o conhecimento científico à aplicação da matemática sobre a regularidade de fatos empíricos.

Para Bergson, embora não se trate de duvidar da efetividade, da utilidade e da segurança proporcionadas pelo conhecimento cientíico desenvolvido a partir de Descartes e Galileu, essas exigências, em vez de favorecer, contradizem a percepção da mudança e geram consequências para a concep- ção do universo em sua totalidade. A confiança no modelo mecanicista se dá às expensas da sua complexidade, e o universo passa a ser reduzido à apreensão espacial da matéria inerte, ou seja, à associação e dissociação de partes idênticas representadas em uma relação de simultaneidade.

Devemos retomar essa história, retrocedendo da modernidade à Antiguidade, e nela reconhecendo que houve dois pensamentos gregos a respeito da mudança. Eles entraram em conflito no domínio da física, prevalecendo aquele que tinha mais proximidade com a representação matemática. O outro pensamento grego sobre a fisica, do qual a filosofia deve, segundo Bergson, se impregnar, teria prevalecido já entre os gregos se, em vez da matemática, a fisica tivesse estreitado seus laços com a biologia e a psicologia.

\section{O espaço prematuramente emancipado}

O texto "A percepção da mudança" revela mais do que um interesse circunstancial, porque a análise que Bergson apresenta das ciências reflete a trajetória do seu pensamento. Depois dos cursos sobre os gregos e da tese complementar o que Aristóteles pensou sobre o lugar, o filósofo se dedicou a dois conjuntos de obras: primeiro os trabalhos de psicologia, Ensaio sobre os dados imediatos da consciência, O riso Ensaio sobre a significação do cômico e Matéria e memória Ensaio sobre a relação entre o corpo e o espírito; em seguida, à biologia em A evolução criadora - obra na qual ele também propõe o maior alcance metafísico do seu pensamento, que em diversos aspectos fora esboçado na obra anterior.

Se é certo que, ao longo da produção dessas obras, Bergson tinha em vista o que primeiramente fizeram os gregos no dominio da física, esses trabalhos poderão em alguma medida reencontrar essa referência em suas conclusões mais abrangentes, ou seja, no plano de uma investigação cosmológica, a qual, por sua vez, revela posições metafisicas que contêm afinidades com a psicologia e a biologia.

Partamos do ponto mais abrangente, mas não

\footnotetext{
7 Essa passagem parece uma resposta à seguinte afirmação de Kant no segundo prefácio da Crítica da razão pura: "O destino não foi até hoje tão favorável que permitisse trilhar o caminho seguro da ciência à metafísica [...]" (KANT, 2018, p. 18).
} 
como foi trabalhado nas obras mais conhecidas, e sim nas articulações da fase em que Bergson ensinou sobre os antigos. Afinal, qual foi a decisão entre os antigos que, oriunda do âmbito da física, determinaria a "percepção da mudança" em geral e, mais especificamente, o modo como fazemos ciência e como compreendemos a filosofia?

No final da tese complementar, encontramos uma comparação entre modernos e Aristóteles:

Nós, como concebemos o espaço infinito com nossa mente, totalmente isento de qualidade e diferença, julgamos que para os corpos, acomodados igualmente ao repouso e à mobilidade, tanto faz que sejam levados para cá ou para lá. O movimento, portanto, julgamos nós, não é algo coeso à natureza do corpo, mas algo estranho a ele acrescentado (2013, p. 159).

Bergson afirma, resgatando a análise do Ensaio, que nós, modernos, "concebemos o espaço" em nossa mente até o infinito. ${ }^{8}$ Aristóteles, diferentemente, compreendeu o espaço a partir do lugar, e este como um atributo do corpo, sempre em relação de contiguidade com outro corpo, compondo uma totalidade de corpos sem intervalos vazios em um espaço finito, cujo limite é o céu. Por que o estagirita teria chegado a essa conclusão? Porque o movimento foi por ele pensado como uma das quatro espécies de mudança (1069b), e toda mudança deveria pertencer à substância ${ }^{9}$ e se dar de um estado ao estado contrário - geração e destruição relativas à essência; aumento e decréscimo relativos à quantidade; alteração relativo à qualidade; e movimento relativo ao lugar: o alto e o baixo, a frente e atrás ou esquerda e direita.

Além dessa explicação encontrada na Metafísica, havia também uma explicação complementar na física. Se o movimento é uma mudança de um lugar a outro, uma tendência de cada corpo a se acomodar em seu lugar natural, só pode haver um lugar determinado para cada corpo, e isto implica que o universo seja finito. A compreensão metafísica da substância e de seus atributos espelha uma compreensão cosmológica. Afinal, em um universo infinito não pode haver lugar natural. A análise de Bergson, então, amplia a relação entre Aristóteles e outras filosofias gregas:

Por causa disso, Aristóteles [...] não ignorou a doutrina de Demócrito sobre o espaço vácuo e infinito, e principalmente louvou Platão por ter sido ele o primeiro a tratar do lugar. As dificuldades, portanto, que nascem do nosso espaço livre e infinito ele pressentiu, ou melhor. julgou-as insuperáveis. Nesse ponto dificilmente nos parecerá ter errado, se atentarmos em que é muito recente, quase de ontem, a distinção entre matéria e forma, na medida em que diz respeito mais à própria cognição que a coisas conhecidas (2013, p. 165).

Devemos atentar ao que Bergson afirma sobre dificuldades que "nascem do nosso espaço livre e infinito", dando a entender que o espaço adquire esses aspectos quando admitimos a distinção entre matéria e forma, sendo relativa à cognição. A concepção de espaço "muito recente, quase de ontem" é encontrada em Kant, filósofo que recusou o espaço como um meio absoluto na realidade, ou como atributo das coisas, e fez dele uma estrutura a priori da intuição, portanto constituido pelo sujeito. ${ }^{10}$

Kant define a matéria como as qualidades dadas aos nossos sentidos. Não poderíamos ter a pretensão de falar dos limites do universo onde nossos sentidos não podem alcançá-la. Bergson, embora acompanhe Kant quanto à

8 Em Kant, entretanto, o espaço não é originariamente concebido, mas intuido, pois, entre outras razões, não se pode conceber o infinito, apenas intuí-lo. "O espaço não é um conceito discursivo ou, como se diz também, um conceito universal das relações das coisas em geral, mas uma intuição pura. Porque, em primeiro lugar, só podemos ter a representação de um espaço único e, quando falamos de vários espaços, referimo-nos a partes de um só e mesmo espaço. [...] É essencialmente uno; a diversidade que nele se encontra e, por conseguinte, também o conceito universal do espaço em geral, assenta, em última análise, em limitações. De onde se conclui que, em relação ao espaço, o fundamento de todos os seus conceitos é uma intuição a priori (que não é empirica). [...] nenhum conceito, enquanto tal, pode ser pensado como se encerrasse em si uma infinidade de representações. Todavia é assim que o espaço é pensado (pois todas as partes do espaço existem simultaneamente no espaço infinito). Portanto, a representação originária de espaço é intuição a priori e não conceito" (2018, p. 65-66).

9 Aristóteles entende o lugar como uma categoria e afirma que "nenhuma das categorias, fora a substância, pode existir separadamente" (1069a).

10 "O espaço não representa qualquer propriedade das coisas em si, nem essas coisas nas suas relações reciprocas; quer dizer, não é nenhuma determinação das coisas inerente aos próprios objetos e que permaneça, mesmo abstraindo de todas as condições subjetivas da intuição [...]. O espaço não é mais do que a forma de todos os fenômenos dos sentidos externos, isto é, a condição subjetiva das sensibilidade, única que permite a intuição externa" (KANT, 2018, p. 67). 
nossa capacidade de constituir um espaço livre e infinito subjetivamente, não respalda, todavia, essa posição crítica, pois deverá voltar a ela para enfrentar a "dificuldade" relativa à duração do universo em sua totalidade integrada. Seu argumento consiste no seguinte: um universo infinito em ato não pode ser concebido como uma unidade e, consequentemente, não pode ter uma duração ${ }^{11}$. Se for infinito, deve ser como potência infinitamente aberta à criação - conclusão metafísica, que certamente o afasta da filosofia crítica de Kant ${ }^{12}$.

Por essa razão, Bergson precisa fazer uma distinção entre o espaço que concebemos em nossa mente como infinito e a extensão da matéria, que ele afirma existir independentemente dos nossos sentidos e que é finita. Em suma, sua concepção metafísica da duração o conduz tanto a uma posição realista sobre a existência da matéria fora do alcance do sujeito quanto à concepção cosmológica de que o universo deve ser finito, embora em evolução ao infinito, ${ }^{13}$ o que não seria possivel em uma concepção materialista e mecanicista.

Aristóteles divergiu dos atomistas quanto à concepção do universo ser infinito, bem como sobre a natureza do movimento. Para os atomistas, o universo é composto por infinitos átomos em movimento aleatório e ininterrupto, que formam corpos mais complexos pelas afinidades geométricas das suas figuras. Teria sido contra os atomistas que Aristóteles formulou sua compreensão do movimento em direção ao lugar natural em um universo finito. Afinal, os filósofos da escola jônica já haviam afirmado o movimento ininterrupto como princípio da realidade, mas, como Aristóteles, em um universo espacialmente finito.

\section{Bergson conclui a respeito de Aristóteles:}

\begin{abstract}
O espaço, portanto, prematuramente emancipado por Leucipo e Demócrito, quis ele assim reduzir aos corpos, para que o lugar substituisse o espaço, a inclusão das coisas finitas nas coisas substituisse o teatro infinito do movimento. Por esse artifício, não apenas sepultou o espaço nos corpos, mas sepultou também, se posso dizer, a própria questão (2013, p. 166-167).
\end{abstract}

O espaço infinito dos modernos fora "prematuramente emancipado" por Leucipo e Demócrito tanto da cosmologia jônica quanto da eleata. Porém, Aristóteles quis encerrá-lo novamente na forma de um atributo dos corpos como modo de encontrar uma explicação melhor para a ordenação do movimento. Sem identificar o movimento às mudanças que se dão na direção do estado oposto, para ele todo movimento seria desordenado. O cosmos seria desordenado. A ordem, portanto, estava associada à permanência dos fins para os quais as coisas mudam.

No centro da discussão está a "percepção da mudança", mas trata-se de quais consequências cada filósofo admite tirar da percepção. Se os filósofos metafísicos inferem modelos para a totalidade do universo, a física moderna, e com ela também a filosofia crítica de Kant, admitirá somente a abstração dos fatos empíricos na forma de leis especificas, os juizos sintéticos a

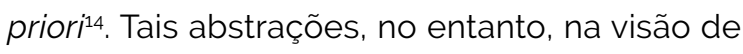
Bergson, contradizem o surgimento contínuo de algo absolutamente novo, em evolução, e que podemos constatar em nossa própria consciência interior, analisada pela psicologia.

Desse modo, Bergson imprime uma distância entre a percepção da mudança e a abstração

\footnotetext{
11 Ver A evolução criadora. Destacamos a seguinte passagem que relaciona totalidade e duração: "O nosso sol irradia calor e luz para além do mais longínquo planeta. E, por outro lado, move-se arrastando consigo os planetas e respectivos satélites, numa determinada direção. O fio que o liga ao resto do universo é sem dúvida muito tênue. Contudo, é por meio desse fio que se transmite, até a menor parcela do mundo em que vivemos, a duração imanente ao todo do universo" (2009, p. 25).

12 O distanciamento de Bergson da filosofia kantiana possui, como pano de fundo, uma distinta atitude filosófica perante as ciências Kant restringe, na Critica da razão pura, o conhecimento filosófico a um caráter propedêutico, para "examinar a razão pura, suas fontes e seus limites" (2018, p. 53). A filosofia transcendental pretende apenas conhecer seguramente suas possibilidades - as quais, por sua vez, correspondem ao modelo da física da época, de Galileu, Torricelli e Stahl.

13 "[...] o universo não está feito, mas se está fazendo incessantemente, e aumenta sem dúvida indefinidamente pela junção de novos mundos" (BERGSON, 2009, p. 265).

14 Por "a priori", Kant compreende aquilo que é necessário e universal. A condição para tornar sínteses de dados da experiência, como simples efeitos da imaginação, em juizos a priori de conhecimento é que o entendimento, a partir de conceitos determinantes, "legisle" sobre os fenômenos: "Por mais exagerado, por mais absurdo que pareça, portanto, dizer que o entendimento é a própria fonte das leis da natureza e, consequentemente, da unidade formal da natureza, uma tal afirmação é contudo verdadeira e conforme ao objeto, isto é, à experiência" (2018, p. 170).
} 
das leis específicas que parecem reinar sobre a matéria inerte, distância a princípio tão grande que é capaz de lançá-lo novamente, como muitos gregos fizeram, à criação de um modelo cosmológico ancorado na mudança. A diferença é que Bergson não se pauta somente nas transformações da natureza, porque tem como referência de igual relevância a duração da consciência interior. Esse é o seu principal deslocamento epistemológico, ao menos aquele por onde ele começa sua produção autoral. Se a psicologia pode oferecer um modelo aplicável à cosmologia, lidamos com uma metafísica que, em vez de ir na direção do espaço, segue a direção da duração até uma origem, onde se encontra o impulso de vida - princípio comum à psicologia, à biologia e à sua metafísica.

\section{O espaço prematuramente conciliado}

Precisamos compreender melhor as afinidades e diferenças entre os antigos e os modernos a fim de explicitar os diferenciais da posição bergsoniana. Quatro ou cinco anos antes da tese complementar em que contrapõe Aristóteles a Demócrito e Leucipo, ele já investigava a filosofia atomista.

O ponto de partida do atomismo é a seguinte ideia: que as qualidades das coisas são puramente aparentes e dizem respeito não à sua natureza, mas à constituição dos nossos órgãos. De onde resulta que, acerca da essência das coisas só podemos nos pronunciar em virtude do raciocínio e não das sensações (2005, p. 244).

Encontramos nos atomistas elementos que nos aproximam parcialmente da filosofia kantiana. As qualidades dos objetos dependem da estrutura perceptiva do sujeito, dos sentidos. Porém, se nos atomistas a falta de correspondência entre a coisa e a sensação se dá entre elementos determinados, em Kant a falta de correspondência se dá porque não podemos ter conhecimento numênico. O entendimento não apreende dados materiais. Seu trabalho é lógico, organizador dos dados que recebe pelos sentidos. Demócrito afirmou como deve ser a realidade da matéria elementar por meio de raciocínios aplicados aos conhecimentos que ele herda da tradição filosófica, de jônios, pitagóricos e eleatas ${ }^{15}$, enquanto Kant se limita à análise de fenômenos. Ambos estão distantes da concepção aristotélica de movimento e indicam que a distinção entre espaço e matéria torna o espaço ilimitado, mas os atomistas são realistas. Como dissemos, eles não se atêm ao que aparece para o sujeito, o fenômeno.

Demócrito pede que lhe concedam duas estruturas, o átomo, com seus diferentes tipos específicos, e o vazio. Além delas, ele acrescenta o movimento ininterrupto, como causa geradora da associação dos átomos, que, em si mesmos, são indivisiveis e imutáveis. Com isso, Bergson pode concluir que: "As diferenças físicas ou qualitativas são reduzidas a diferenças quantitativas ou matemáticas" (2005, p. 246). O problema que fica em aberto em sua leitura dos atomistas é como pode haver simples combinação mecânica entre elementos em um sistema aberto ao infinito. Isso exigiria a existência de sistemas fechados em um universo infinito, como um multiverso.

Da perspectiva da história do pensamento, o que mais interessa é verificar a relação que Bergson estabelece entre os atomistas e o mecanicismo moderno: "Se a filosofia grega tivesse seguido a via de Demócrito, o espírito sutil dos gregos teria chegado a descobertas feitas quinze ou vinte séculos mais tarde" (2005, p. 251). Por muitos séculos, a via de compreensão da realidade - sobretudo quanto à explicação do movimento - foi a aristotélica, mas o mecanicismo moderno fora esboçado quando os atomistas reduzem a mudança qualitativa a combinações quantitativas. Bergson sugere que outros modelos atomistas, como os que encontramos em Dalton, Thomson, Rutherford, Bohr, entre outros, talvez pudessem ter surgido antes.

Em uma passagem das Aulas de psicologia e de metafísica, encontramos outra explicação para essa afirmação, que relaciona os atomistas, desta vez, a Descartes: "O que há de comum entre as hipóteses de Descartes e as de Demócrito? Um e outro consideram a matéria como desprovida de

15 Os átomos são semelhantes às mônadas pitagóricas por serem unidades indivisíveis, possuem as propriedades do ser segundo os eleatas, de serem eternos e imutáveis, mas estão em perpétuo movimento no espaço, conforme a realidade móvel dos jônios. 
iniciativa, como alguma coisa totalmente inerte, passiva, eternamente submissa às leis inflexiveis da mecânica" (2014, p. 371). A aproximação de Demócrito é com "quinze ou vinte séculos mais tarde", porque se trata de uma aproximação tanto com Descartes quanto com Kant, além dos físicos acima mencionados.

Resta ver como Bergson se posiciona frente às alternativas da tradição. Para afirmar o espaço infinito, Kant não requer uma realidade infinita. Porém, ao autorizar a possibilidade de que o conjunto dos fenômenos seja finito, embora o mundo seja aberto ao infinito como forma pura da intuição, Kant deixa uma brecha para o desenvolvimento da concepção cosmológica de Bergson - à sua analogia entre psicologia e cosmogonia: "À nossa distinção entre matéria e forma segue-se também que, se todas as coisas forem plenas em um mundo finito, mesmo assim, nosso espaço possa dizer-se vácuo e também infinito" (BERGSON, 2013, p. 155, grifo do autor). Segue-se, para Bergson, não apenas que possamos intuir ou conceber um espaço vácuo e infinito, como também que um universo pleno e finito possa ser aberto ao infinito pela incessante criação.

Demócrito explicou a constituição de formas infinitas a partir de formas limitadas combinadas de maneira infinita em razão da quantidade infinita de átomos. Kant suspendeu o juízo a respeito da finitude e da constituição elementar da matéria, mas oferece meios de resguardar a infinitude da forma, sendo esta constituida pelo sujeito. Bergson, por sua vez, faz da abertura ao infinito algo que deve não apenas ser uma possibilidade subjetiva, mas algo que deve ter uma implicação metafísica para o universo, ou seja, a de que ele está em evolução. As condições para o desenvolvimento desse tema já aparecem na tese complementar:

Como, portanto, nossos filósofos constituiram dois modos de existência, um para o que se compõe de matéria e forma, outro para a forma livre e independente, entendemos que é pos- sivel que cada composto de matéria e forma seja finito, mas que a forma esteja aberta ao infinito (2013, p. 155).

Se Kant propõe que o espaço infinito é independente da extensão da matéria, em 1907, ao resgatar a investigação metafísica do universo, Bergson proporá que a matéria deve ser limitada em sua totalidade para que possa ter uma duração, mas suas formas estão abertas à evolução infinita na própria realidade e não somente como possibilidade subjetiva.

\section{Tales e o mobilismo}

Na introdução à primeira edição francesa onde foi publicado o Caderno Preto, ${ }^{16}$ Henri Hude propõe a inversão da filosofia de Zenão de Eléia como referência entre os gregos para explicar a "intuição seminal" do "bergsonismo". ${ }^{17}$ De fato, em seus grandes livros, o filósofo francês recorre mais ao paradoxo de Zenão, que confunde o movimento com a representação do espaço, do que à análise da filosofia jônica. Entretanto, uma vez reconhecido o antagonismo entre as escolas da Jônia e a escola de Eleia, é estranho ver na sugestão de Henri Hude que o bergsonismo é uma reação original - uma "intuição seminal" - que inverte o pensamento eleata, como se a filosofia eleata não fosse ela mesma a inversão da filosofia que intui a mudança como princípio geral da realidade. Em vez de recorrer a uma negação da negação, como fez Hude, propomos uma investigação das afinidades e diferenças entre o bergsonismo e o pensamento jônico.

O início da escola jônica, bem como de toda a filosofia ocidental, remonta a Tales de Mileto. Para Bergson, o único testemunho que tem valor é o de Aristóteles, o qual afirma que Tales foi famoso como geômetra e astrônomo, e que previu o eclipse de 585 a.C. Se isto é certo, o primeiro filósofo possuía um domínio profundo da matemática aplicada à astronomia, o que contraria a

\footnotetext{
16 Trata-se de uma referência ao caderno de capa preta onde estudantes anônimos anotaram o curso de 1884-1885, na Universidade de Clermont-Ferrand, e que seria inserido com o título "História da filosofia grega" na obra Cursos sobre a filosofia grega.

17 Henri Hude afirma: "O final da lição sobre Zenão de Eléia no Caderno Preto é a seguinte: 'Seja como for, é sempre preciso admitir, em presença do movimento, ou que a realidade é absurda ou que ela é ilusória', o que traz em baixo-relevo, ou como que invertida, a intuição seminal do bergsonismo. Temos ai o principal documento filosófico sobre o bergsonismo nascendo, ou melhor, a ponto de nascer" (HUDE, 2005, p. XIX-XX)
} 
ideia, baseada na física aristotélica, de que os Antigos não relacionavam matemática e física. No entanto, o que mais importa notar é que esse conhecimento não determinou um primado da matemática no conhecimento da natureza, como ocorre na modernidade.

Ao afirmar que "tudo é água", Tales deve ter observado que a água é um princípio essencial do corpo vivo e que aquilo que morre resseca, o que aproxima sua cosmologia da biologia. Mas Bergson questiona: "Como saíram as coisas da água?" (2005, p. 191). Aristóteles dá a entender que Tales teria sido um filósofo dinamista, cuja característica é fazer "as coisas saírem desse principio por condensação e rarefação". (2005, p. 191) Trata-se, porém, de uma explicação tradicionalmente atribuida a Anaximenes, de modo que é preciso ter em vista o risco de projetar sobre uma filosofia mais antiga o que pode ser próprio de outra posterior. De todo modo, o critério de rarefação e condensação, seja em que momento surgiu entre os jônios, é uma explicação semelhante àquela aventada por Bergson em A evolução criadora quanto à distinção entre matéria e "consciência" ou "querer" (no sentido de um princípio metafísico tradicionalmente associado ao espírito), ou seja, que a diferença entre eles talvez seja intensiva. ${ }^{18}$

A segunda sentença se volta precisamente a esse tema. Aristóteles dela afirma que, segundo Tales, "a alma circula através do mundo, que o mundo é animado, kósmos émpsykhos" (2005, p. 191). E, dessa vez, encontramos uma aproximação entre a cosmologia e a psicologia.

No capítulo sobre os estoicos, do curso de filosofia grega de 1894-1895, no Liceu Henri IV, Bergson retoma essa leitura dos jônios:

À medida que essa ideia se desenvolvia, reaproximava-se, por um progresso lógico, da física dos antigos jônios. E foi assim que o estoicismo regenerou, ao espiritualizá-la, ao conferir-lhe uma alma, ao fazer com que a razão nela penetrasse profundamente, a doutrina hilozoista dos jônios (2005, p. 158).
É provável que a ideia introduzida pelos estoicos tenha sido não a de que o espírito circula no mundo, e de que a matéria seja dotada de espírito ou que seja ela mesma em alguma medida intensiva espírito, mas a de que esse espírito deve ser compreendido como "razão". A origem da associação entre matéria e espirito remonta a Tales, que define a água como o princípio material que atua em todas as coisas. A qualidade fundamental da água é o mobilismo, que, tanto nos jônios quanto em Bergson, é uma qualidade do espírito. Encontramos uma primeira formulação da doutrina hilozoísta, segunda a qual o universo material possui alma. A água é, portanto, o elemento que reúne, em uma sentença, a física, a metafísica, a biologia e a psicologia.

O que em grande medida explica a maior admiração de Bergson pelo filósofo seguinte, Anaximandro, que foi discípulo de Tales, é o fato de Tales não ter legado uma resposta a um problema fundamental para Bergson: "como saíram as coisas da água?" Como a diversidade pode derivar de uma unidade?

\section{Anaximandro e o princípio indeterminado}

No curso sobre filosofia grega proferido nos anos de 1894 e 1895 no Liceu Henri-IV, Bergson geralmente reafirma os principais elementos tratados no Caderno Preto alguns anos antes: "Os filósofos jônios preocupam-se, então, com a determinação do princípio material das coisas" (2005, p. 83). Mas não apenas. "Os jônios notaram a mudança constante e, de modo inverso, os eleatas compreenderam e deslindaram as propriedades lógicas do Ser". (2005, p. 89) A partir de então, os gregos procuraram formas diferentes de conciliar o legado de jônios e eleatas. Se Platão recorreu à separação entre mundo sensivel e mundo inteligivel, os atomistas recorreram à concepção de um átomo cujas propriedades são as do ser nos eleatas, embora em movimento

\footnotetext{
18 No terceiro capítulo da referida obra, Bergson aventa a hipótese - por diversos comentadores referida como "monista" - de que todas as coisas derivam de um mesmo principio vital, nesse momento referido como "consciência" e "querer": "Colocarei, pois, no cume da hierarquia, a ordem vital e, em seguida, como uma diminuição ou uma complicação menos elevada daquela, a ordem geométrica [...]" (2009, p. 259). Trata-se, evidentemente, de uma abordagem dinamista do dualismo entre matéria e espirito. No entanto, cabe observar que Bergson a apresenta como uma "suposição" que sempre exige, assim como no ar (rarefeito ou condensado) de Anaximenes, duas direções: tensão ou extensão; liberdade ou necessidade.
} 
ininterrupto, como propunham os jônios.

Uma das grandes diferenças presentes nos dois trabalhos é que, no curso do Liceu, o maior representante do pensamento Jônio é Heráclito, enquanto, no Caderno Preto, é Anaximandro. Devemos considerar possiveis razões para isso. Em primeiro lugar, há nos índices dos cursos uma diferença de recorte histórico e temático. 0 Caderno Preto é dedicado ao pensamento que vai de Tales a Platão. No curso proferido no Liceu Henri-IV, Bergson realiza apenas uma pequena introdução a toda "filosofia grega antes dos sofistas", aprofundando-se em análises sobre os sofistas, Sócrates, Platão, Aristóteles e em três escolas: cinismo, estoicismo e escola de Alexandria. A ênfase em Anaximandro favoreceria a unidade de uma primeira fase enquanto a ênfase em Heráclito favoreceria a unidade da fase seguinte.

A razão principal é que seria possivel encontrar em Heráclito mais elementos de uma antropologia, enquanto, para Bergson, Anaximandro seria fundamentalmente um físico. Sabemos, porém, que há sentenças de Anaximandro que reúnem aspectos morais, psicológicos ou antropológicos a uma concepção cosmológica, porém a referência delas é Simplício, e Bergson se limita à abordagem aristotélica.

Para evitar a dificil questão de determinar em quem reside a originalidade de algumas ideias, muitas vezes Bergson lança mão da expressão "jônios", fazendo menção ao conjunto de questões desenvolvidas por Tales, Anaximandro, Anaximenes e Heráclito, mas devemos dentro do possivel buscar distingui-los.

O que reúne os jônios é o fato de serem dinamistas e o de terem buscado principios materiais correspondentes a esse pressuposto. O mecanicismo, que é a mudança explicada pela diferente combinação de elementos imutáveis, só poderia ter aparecido depois do surgimento da escola eleata, que proclama a imutabilidade do ser. Assim são a filosofia atomista e a física moderna. Para os dinamistas, não há nada que seja absolutamente imutável. Tudo está em movimento no espaço e ao mesmo tempo se transmuta. ${ }^{19}$ Mas como o princípio gera a diversidade das coisas? Estariam todos de acordo com relação à explicação expressa por Anaximenes?

No Liceu Henri-IV, Bergson afirma que "o filósofo da Escola da Jônia por excelência foi Heráclito de Éfeso" (2005, p. 84). Na conclusão de sua análise de Heráclito no Caderno Preto, no entanto, ele sugere a primazia de Anaximandro:

\begin{abstract}
Os elementos essenciais da filosofia de Heráclito já se encontram em seus predecessores. A ideia de mudança encontra-se nos jônios em geral; a de separação, de substância infinita, de mudança perpétua, encontra-se em Anaximandro. A explicação do todo por meio de uma substância determinada encontra-se em Anaximenes.

Mas a originalidade do sistema consiste na importância atribuída àquilo que, até então, tinha sido apenas acessório: a ideia de mudança, de transformação universal. Heráclito põe-se claramente o novo problema: aquele que consiste em procurar como as coisas foram feitas, e não apenas de que são feitas (2005, p. 202).
\end{abstract}

A segunda parte da passagem mencionada parece enigmática, pois sugere que os filósofos anteriores, Anaximandro e Anaximenes, não teriam explicado "como as coisas foram feitas", questão que Bergson indicou já existir em Tales quanto à rarefação e condensação. As posições são claramente conflitantes, e devemos nos aprofundar mais na leitura que Bergson apresenta de Anaximandro no Caderno Preto.

De início, Bergson situa Anaximandro como compatriota de Tales e tendo nascido por volta de 611 a.C. Diz-nos que sua obra Da Natureza foi o primeiro escrito filosófico dos gregos. A análise começa com a indicação do princípio defendido por Anaximandro. Não mais a água, ele seria to $\alpha \pi \varepsilon$ ıov, termo que terá muitos significados, mas

\footnotetext{
19 Na conferência de 1911, há diversas passagens que claramente colocam Bergson ao lado dos jônios: "A bem dizer, não há nunca imobilidade verdadeira, se entendemos com uma isso ausência de movimento". O movimento é a própria realidade e o que chamamos de imobilidade é um certo estado de coisas análogo àquele que se produz quando dois trens caminham com a mesma velocidade, no mesmo sentido, em duas vias paralelas [...]" (2006, p. 166). E ainda: "Há mudanças, mas não há, sob a mudança, coisas que mudam: a mudança não precisa de um suporte. Há movimentos, mas não há objeto inerte, invariável, que se mova: o movimento não implica um móvel" (206, p. 169) Finalmente: "O que é o 'móvel' ao qual nosso olho vincula o movimento, como que a um veiculo? Simplesmente uma mancha colorida, que sabemos bem que se reduz, em si mesma, a uma série de oscilações extremamente rápidas. Esse pretendo movimento de uma coisa não é na realidade mais que um movimento de movimentos" (2006, p. 171).
} 
que Bergson primeiramente traduz por "o infinito".

Aristóteles nos diz muito claramente (Física, III, 4) que não se trata do infinito substância, mas do infinito atributo. O que significa que, segundo Anaximandro, o fundo das coisas não é o infinito abstrato e metafísico. É uma certa matéria que tem por característica própria não ser limitada. Esse infinito é apenas um acidente da matéria (2005, p. 192).

Cabe concluir que, na compreensão de Bergson, o infinito de Anaximandro é um atributo de uma substância material. Mas seria um atributo acidental? Como Aristóteles poderia admitir que essa substância seja definida por uma qualidade acidental? Qual seria, então, a sua essência? Parece, ao contrário, que essa propriedade deve ser essencial, de modo que, mesmo sendo essa matéria limitada, algo de essencial nela seja infinito - a "mudança perpétua". A passagem prossegue: "Essa matéria infinita de que Anaximandro fala era muito provavelmente uma mistura indeterminada, mas homogênea, que não é tal ou qual elemento em particular, mas que possui vagamente, na condição de tendência, as características da maior parte delas" (2005, p. 192).

Essa matéria é uma mistura homogênea, mas que não é efeito, resultado de nada determinado. Afinal, nesse caso ela não seria um princípio, $\alpha \rho \chi \eta$. A mistura é um modo de afirmar a indeterminação que essencialmente a constitui em sua abertura ao infinito. De fato, é apenas "na condição de tendência" que os elementos particulares devem estar contidos nela. A questão "como?" - que mais inquieta Bergson e que supostamente marca a originalidade de Heráclito - é o que encontramos exposto em seguida quando analisa Anaximandro:

Como saíram as coisas desse elemento primitivo? [...] Trata-se de saber se Anaximandro é um mecanicista ou um dinamista. O que se quer dizer com isso? Dá-se o nome de filósofo dinamista àquele que admite que a matéria é capaz de se transformar qualitativamente, de se tornar algo diferente do que ela é. O mecanicismo, ao contrário, supõe que as coisas podem combinar-se diferentemente umas com as outras, mas que cada uma delas permanece eternamente aquilo que ela é: a transformação é impossivel. [... Um texto de Simplício dá a entender que Anaximandro teria sido claramente mecanicista. As coisas teriam saido da mistura primitiva por via de simples separação. Não obstante, um texto de Aristóteles (Metafísica, XII, 2, 1069b) diz positivamente o contrário. Eis a tradução desse texto: O ser não pode sair do não-ser, nem mesmo acidentalmente, mas tudo sai de algo que já é, ainda que o ser saia da simples potência. E tal é o $\mu$ i $\mu \alpha$, de Empédocles e de Anaximandro". Nesse trecho, Aristóteles indica-nos claramente que, na mistura de Anaximandro, os elementos estão contidos em potência, e não em ato. Dela sairam, portanto, por via de transformação (2005, p. 193-194).

Em primeiro lugar, se esse princípio é um todo material, ele não pode ser ilimitado em ato. 0 infinito deve, então, ser uma direção. Tal mistura, portanto, na qual os elementos coexistem os conteria apenas "em potência, e não em ato". Eles saíram por via de transformação, seguindo uma "tendência". Mas poderia essa tendência ser compreendida à luz da causa final aristotélica?

Impressiona ver que o próprio Aristóteles parece atribuir a Anaximandro uma ideia ausente na história da filosofia que ele reconstitui no livro I da Metafísica - na qual surpreendentemente omite Anaximandro - e que é fundamental para o seu sistema. Fica um significativo enigma: teria Anaximandro antecipado os fundamentos de ato e potência da metafísica aristotélica ou Aristóteles se utiliza de um elemento do seu sistema para interpretar Anaximandro? Problema não esgotado por Bergson.

O que mais impressiona reconhecer é que a posição de Anaximandro frente a Aristóteles, bem como entre a ciência antiga e a moderna, pudesse antecipar tantas discussões decisivas no pensamento do próprio Bergson. Afinal, uma separação que não seja apenas mecânica, quantitativa, material, só pode ser uma separação na constituição da forma - por "transformação". Se falamos de um principio indeterminado, que contém o infinito não em seu aspecto material, mas de como a matéria limitada contém em potência infinita as formas que dela surgem, afastamo-nos, então, de Aristóteles e nos aproximamos das ideias presentes em A evolução criadora. Nela, aliás, encontramos um significado especifico de tendência: "Porque a vida é tendência, e a essência de uma tendência é desenvolver-se em forma de girândola, criando, pelo simples fato do seu 
crescimento, direções divergentes entre as quais o seu impulso se partilhará" (2009, p. 116-117). ${ }^{20}$

Se é certo que se trata de uma substância material, lidamos com uma matéria limitada, mas potencialmente aberta para infinitas formas; para algo sempre novo. Demócrito afirmara o infinito das formas a partir do infinito da matéria, e em Anaximandro as formas são potencialmente infinitas mesmo que a matéria seja finita. Demócrito se aproximaria mais do que qualquer outro filósofo antigo dos modernos por ser um mecanicista, enquanto Anaximandro, por ser um dinamista voltado às formas novas, estaria mais próximo do pensamento do próprio Bergson do que estão os modernos.

\section{Da natureza}

Vimos em O que Aristóteles pensou sobre o lugar que é a abertura para formas infinitas, mesmo se o mundo for materialmente finito, o que distingue os modernos do pensamento aristotélico, e que a solução naquele momento foi tornar a forma subjetiva. Se lidamos com formas infinitas no tempo para além da combinação mecanicista ${ }^{21}$, avançamos ao bergsonismo. Afinal, mesmo que em determinado momento da história do mundo - o universo em ato - a quantidade de matéria seja limitada, as formas são abertas ao infinito na própria realidade imanente, para além da constituição do sujeito. Falamos de criação de formas e de uma concepção de evolução para além também da evolução das espécies de Darwin - uma evolução cosmológica, "sem começo e sem fim", em que o próprio universo é como um ser vivo. ${ }^{22}$ Bergson oferece mais elementos para compre- endermos a cosmologia de Anaximandro e para que possamos compreender a afinidade do filósofo antigo com o seu pensamento. A formação do mundo possuiria fases. O que primeiro saiu da mistura, processo que, no entanto, não pode ser compreendido cronologicamente por ser "sem começo e sem fim", "foi o quente e o frio", de onde se poderia antecipar talvez a enorme importância que o fogo terá em pensadores como Heráclito, Empédocles, Demócrito e nos estoicos. Pode-se antecipar também as ideias de condensação e rarefação, de Anaximenes.

Bergson, em seguida, afirma que "o número de mundos, aliás, é infinito". E em seguida propõe uma estranha questão: "Estaria Anaximandro querendo se referir a uma infinidade de mundos sucessivos ou de mundos simultâneos?" (2005, p. 194-195). Ora, sendo a matéria limitada conforme sua própria afirmação de que ela compõe um todo em ato, como os mundos poderiam ser infinitos simultaneamente? Além disso, embora Bergson não o diga, sabemos que Anaximandro foi o primeiro pensador responsável por sugerir que a Terra paira estável no centro do universo por não ter para onde cair, simplesmente em razão da sua equidistância a todos os pontos do universo. ${ }^{23}$ Este seria necessariamente esférico e, portanto, finito. É evidente que os mundos apenas poderiam ser infinitos sucessivamente, como novas totalidades em ato, na variação da matéria limitada e indeterminada para uma infinidade de formas que ela contém em potência à criação infinita. ${ }^{24}$

O mesmo raciocínio que determina a unidade do universo em razão da sua finitude espacial, porém a abertura ao infinito no tempo, aplica-se,

\footnotetext{
20 Ao analisar a ideia de tendência em A evolução criadora, Bergson utiliza o critério da "separação" que também esteve presente na explicação das transformações do ápeiron de Anaximandro. Nos dois momentos, trata-se do problema de "como as coisas surgem". A tendência como "girândola" ou "ramificação" resgata a "separação" de Anaximandro.

${ }_{21}$ Vale ressaltar que um sistema mecanicista fechado não poderia ir além da analise combinatória, de modo que o infinito no mecanicismo requer uma quantidade infinita de matéria, como propuseram os atomistas gregos.

22 É importante observar que Bergson faz uma distinção entre "criação de formas" e "corrente vital". Nesse sentido, a forma é uma conquista do esforço oriundo da corrente vital, mas que, por necessitar da matéria para se realizar, cede em seu esforço de liberdade à necessidade de permanecer que a caracteriza. Esse processo explica tanto o surgimento quanto a mudança da forma.

23 Ver As origens do pensamento grego, de Jean-Pierre Vernant: "Anaximandro localiza a terra, imóvel, no centro do universo. Acrescenta que se ela permanece em repouso nesse lugar, sem ter necessidade de nenhum suporte, é porque está a igual distância de todos os pontos da circunferência celeste e não tem nenhuma razão para ir para baixo mais que para cima, nem para um lado mais que para outro. Anaximandro situa, pois, o cosmos num espaço matematizado constituído por relações puramente geométricas" (1998, p. 96).

${ }_{24}$ A forma esférica do universo, que muitos autores, mas não Bergson, atribuem a Anaximandro, não contraria a indeterminação das formas porque ela não se mantém idêntica a si mesma. Não se trata de uma figura determinada pelo contorno e vazia de preenchimento, mas de uma crescente produção de heterogeneidade no tempo.
} 
em Bergson, para a necessidade de que o universo seja finito em ato em razão da sua duração, embora aberto em potência à criação incessante: "Mas o que é admirável em si, o que deveria ser motivo de espanto é a criação incessantemente renovada que o real, no seu todo indiviso, efetua avançando [...]" (2009, p. 240).

Ao finalmente falar da importância histórica de Anaximandro, encontramos também essa importância para seu próprio pensamento.

[...] percebendo que o número das transformações é infinito, irá atribuir a infinidade a essa matéria. Essa teoria deduz-se facilmente da primeira (de Tales). Mas Anaximandro introduziu na filosofia a ideia de matéria indeterminada, a de movimento eterno, a de separação que consiste em uma especificação. Ora, essas ideias são importantes: são as da teoria evolucionista. O que H. Spencer chama de passagem do homogêneo

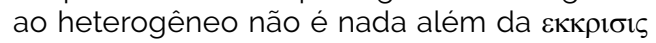
(separação) de Anaximandro (2005, p. 195).

O que há de infinito no ápeiron são "suas transformações possiveis". Ele deve ser tão mais indeterminado, mais livre, mais aberto a possibilidades, quanto mais indeterminado for o principio. Assim, Anaximandro separou da matéria a sua forma e deu a esta, diferentemente de Aristóteles, o caráter de ser potencialmente sempre nova. O que se perde com isso é a diferença entre essência e acidente, que é um modo de conciliação com os eleatas. Porque o movimento é eterno, porque ele não pode cessar, como diz a lei mais fundamental dos jônios, é necessário que o equilibrio não seja jamais estático. Bergson revela ainda mais, que Anaximandro concebeu "a separação que consiste em uma especificação" e diz que essas ideias são as da teoria evolucionista, e esse sentido de evolução estará mais próximo do pensamento do próprio Bergson do que esteve de Spencer. ${ }^{25}$

O ápeiron, de Anaximandro, não apenas como principio indeterminado, mas como principio que dirige ou governa a produção de todas as coisas no sentido ou tendência à indeterminação, remete à tese central de A evolução criadora:

O impulso de vida de que falamos consiste, em
suma, em uma exigência de criação. Não pode
realizar uma criação total, porque encontra à
sua frente a matéria, isto é, o movimento inverso
ao seu. Mas apodera-se dessa matéria, que éa
própria necessidade, e tende a nela introduzir
o máximo possivel de indeterminação e de
liberdade (2009, p. 275).

A indeterminação da matéria, que Anaximandro ensinou a Aristóteles, não implica que ela seja um substrato de formas imutáveis propagadas de geração em geração, pois a indeterminação do princípio deve ser tão material quanto formal. Não se pode substituir a forma imutável compartilhada entre as gerações - como o homem que gera outro homem - por uma forma final a ser alcançada após um processo evolutivo previsivel. ${ }^{26}$ Há tanta indeterminação no princípio material quanto há na evolução das formas. $E$ esse é mais um ponto de convergência entre as filosofias de Anaximandro e de Bergson, que afirma: "Real é a mudança contínua de forma" (BERGSON, 2009, p. 329).

O universo, por sua vez, também não possui, em sua totalidade, uma forma imutável. Afirmar sua evolução não significa que alcançará uma forma cabal. Bergson compreende que a mudança das formas está em todo "impulso de vida", nos seres vivos e na totalidade do universo: "[...]um imenso reservatório de vida deve lançar incessantemente jatos, cada um dos quais, ao cair, é um mundo" (2009, p. 271).

Podemos relacionar esse "imenso reservatório de vida" ao ápeiron de Anaximandro, infinito e indeterminado, mas se Bergson afirma que dele saem múltiplos mundos, não há razão para crer que eles não constituam uma totalidade. Embora sejam divergentes as direções para a indeterminação, pela duração eles se ligam a uma origem comum, e é nesse sentido que compõem

\footnotetext{
25 Bergson pretende substituir "o falso evolucionismo de Spencer - que consiste em recortar a realidade atual, já evoluida, em pequenos pedaços, igualmente evoluidos; em seguida recompô-la com esses fragmentos, oferecendo antecipadamente tudo o que se quer explicar" por um verdadeiro evolucionismo "no qual a realidade seria seguida em sua geração e em seu crescimento" (2010, p. 12). 26 "A vida no seu conjunto, considerada como uma evolução criadora [...], transcende a finalidade, se entendermos por finalidade a realização de uma ideia concebida ou concebivel por anteçipação. O molde da finalidade é, portanto, demasiado estreito para a vida na sua totalidade" (BERGSON, 2009, p. 246).
} 
uma totalidade. Nos jônios a totalidade é, assim como a mudança e o movimento, uma categoria fundamental do pensamento, e o conceito bergsoniano de duração é capaz de esclarecer como esses dois aspectos se articulam. Ainda que Anaximandro tenha afirmado que o mundo é esférico, não há razão para duvidar de que esse ilimitado reservatório de vida não pudesse ser a fonte para sua incessante ampliação.

O tempo liberado de uma finalidade (télos) atemporal é um importante diferencial, entre os filósofos modernos, da concepção de duração proposta por Bergson. Portanto, ao resgatar o princípio do ápeiron, concebido por Anaximandro no seio da filosofia jônica, Bergson o conduz a uma clareza e a relações não enunciadas no plano da liberdade - como problema moderno —, sobretudo no domínio psicológico, como fica evidente na análise desenvolvida desse conceito em seu primeiro livro, o Ensaio sobre os dados imediatos da consciência.

\section{Considerações finais}

Em "A percepção da mudança", de 1911, Bergson afirma: "Todos, antigos e modernos, concordam em ver na filosofia uma substituição do percepto pelo conceito" (2006, p. 152). Em A evolução criadora, publicada quatro anos antes, Bergson apresenta no quarto capítulo as bases dessa afirmação: "A filosofia antiga assenta-se necessariamente no seguinte postulado: há mais no imóvel do que no movente, e passa-se, graças a uma diminuição ou atenuação, da imutabilidade ao devir" (2009, p. 344). O conjunto dos sistemas metafísicos fica reduzido à busca de essências imutáveis, caindo os jônios no esquecimento.

Quando Hude formula a hipótese de que a filosofia de Bergson é uma inversão ou o negativo da filosofia de Zenão, ele tem em vista o enorme peso dado por Bergson ao eleata em suas grandes obras, destacadamente em A evolução criadora. O que causa estranhamento é perceber a omissão dos jônios e ver que Bergson os conhecia desde os cursos que ofereceu na juventude. Desse modo, ao seguir as obras principais, Hude subestima os próprios cursos que editou.

É certo que assumir as ideias de Bergson como absolutamente originais conferem maior destaque à sua filosofia, e é nesse sentido que os gregos são recuperados em suas obras principais, para serem contrastados com suas ideias. Eles são tratados como "os antigos" e reunidos por supostamente concordarem na recusa da mudança:

Para os antigos, com efeito, o tempo é teoricamente desdenhável, porque a duração de uma coisa só manifesta a degradação da sua essência: é dessa essência imóvel que a ciência trata. Sendo a mudança apenas o esforço de uma Forma em direção da sua própria realização, a realização é tudo quanto nos interessa conhecer (2009, p. 373).

Quanto às diferenças entre a ciência antiga e a moderna, embora haja concepções de espaço radicalmente distintas, elas convergem em um aspecto: a redução da mudança à representação espacial: "Em resumo, se a física moderna se distingue da antiga na medida em que considera qualquer momento do tempo, por outro lado assenta inteiramente na substituição do tempo-invenção pelo tempo-extensão" (2009, p. 372).

Essa afinidade reside principalmente na relação entre representação espacial e inteligência prática. Como a ciência busca o domínio dos fenômenos, é esperado que ela represente as sucessivas transformações do mundo como partes que se repetem para favorecer a previsibilidade e o controle. ${ }^{27}$ Porém, segundo Bergson, os recortes que as ciências física e matemática operam na realidade conduziram-nos tanto a um tratamento mais útil e seguro da realidade, quanto a uma concepção filosófica mais vulgar do universo em sua totalidade. De um universo-máquina a um universo-bomba, que infla, dispende energia e esfria, trata-se de uma realidade fragmentada, descontínua, na forma

\footnotetext{
27 "Mas toda a nossa inteligência se insurge contra essa ideia da originalidade e a imprevisibilidade absoluta das formas. A nossa inteligência, tal como a evolução da vida a modelou, tem como função essencial iluminar o nosso comportamento, preparar a nossa ação sobre as coisas, prever, para uma dada situação os acontecimentos favoráveis ou desfavoráveis que poderão sobrevir. [...] A ciência leva essa operação ao mais alto grau possivel de exatidão e de precisão, mas não altera o caráter essencial dela. Tal como o conhecimento usual, a ciência só retém das coisas o aspecto repetição" (2009, p. 44)
} 
de partes de espaço e de tempo que recusam o principio da mudança criadora "sem começo e sem fim", que nossos sentidos testemunham por toda parte e principalmente que intuímos em nossas próprias consciências.

Para contornar a filosofia crítica kantiana, como uma expressão da inteligência prática enraizada na física matemática, ${ }^{28}$ Bergson precisou inverter a direção em que se desenvolveu esse pensamento até reencontrar sua origem, onde descobriu uma cisão metafísica decisiva e uma interlocução distinta, mas igualmente fecunda, com a filosofia jônica, ainda que ela seja menos explicita do que poderia ser.

\section{Referências}

ARENT, H., A vida do espirito. Trad. Cesar Augusto de Almeida, Antônio Abranches e Helena Martins. Rio de Janeiro: Civilização Brasileira, 2008.

ARISTÓTELES. Metafisica. Trad. Leonel Vallandro. Porto Alegre: Editora Globo, 1969.

BARNES, J. Filósofos Pré-Socráticos. Trad. Julio Fische. São Paulio: Martins Fontes, 1997.

BERGSON, H. A evolução criadora. Trad. Adolfo Casais Monteiro. São Paulo: Editora UNESP, 2009.

BERGSON, H. Aulas de Psicologia e de Metafísica. Trad. Rosemary Abilio, São Paulo: Martins Fontes, 2014.

BERGSON, H. Cursos sobre a filosofia grega. Trad. Bento Prado Neto. São Paulo: Martins Fontes, 2005.

BERGSON, H. Ensaios sobre os dados imediatos da consciência. Trad. João da Silva Gama, Lisboa: Edições 70, 2011.

BERGSON, H. O Pensamento e o movente. Trad. Bento Prado Neto. São Paulo: Martins Fontes, 2006.

BERGSON, H. O que Aristóteles pensou sobre o lugar. Trad. Anna Lia de Almeida Prado. Campinas: Editora Unicamp, 2013.

DELEUZE, G. Bergsonismo. Trad. Luiz Orlandi. São Paulo: Editora 34, 2012.

FOUCAULT, M. O nascimento da clínica. Trad. Roberto Machado. Rio de Janeiro: Forense Universitária, 2011.

HEIDEGGER, Martin. Ser e tempo. Márcia Schuback. Petrópolis: Vozes, 2006.

KANT, I. Crítica da razão pura. Trad. Manuela Pinto dos Santos e Alexandre Fradique Morujão. Lisboa: Calouste Gulbenkian, 2018.
LEOPOLDO E SILVA, F. Bergson - intuição e discurso filosófico. São Paulo: Loyola, 1994

MOSSÉ-BASTIDE, R-M. Bergson et Plotin. Paris: Presses Universitaires de France, 1959.

PRADO JUNIOR, B. Presença e campo transcendental: consciência e negatividade na filosofia de Bergson. São Paulo: Editora da Universidade de São Paulo, 1988.

VERNANT, J.-P. As origens do pensamento grego. Trad. Ísis da Fonseca. Rio de Janeiro: Bertrand Brasil, 1998.

WORMS, F. Bergson ou les deux sens de la vie. Paris: Presses Universitaires de France, 2004.

WORMS, F. Le vocabulaire de Bergson. Paris: Ellipses, 2013.

\section{Tomás Prado}

Doutor em Filosofia (PUC-Rio), no Rio de Janeiro, RJ, Brasil; com experiência de pesquisa na Universidade Paris 1 Panthéon-Sorbonne, França; pós-doutor em Filosofia pela Universidade Federal de São Paulo (UNIFESP), em São Paulo, SP, Brasil. Professor visitante de Filosofia na Universidade Federal do ABC (UFABC), em Santo André, SP, Brasil.

\section{Endereço para correspondência}

Tomás Prado

Universidade Federal do ABC - $\mathrm{CCNH}$

Rua Arcturus, 3, sala S-233

Jardim Antares, 09606070

São Bernardo do Campo, SP, Brasil

28 Na Crítica da razão pura, Kant afirma que a metafísica deve ser o inventário da razão, e que esta encontra seus objetos a priori na física e na matemática (KANT, 2018, p. 16). Portanto, a metafísica deveria ser determinada pelos objetos da física e da matemática. É fundamentalmente contra esse pressuposto que Bergson se coloca em sua análise das ciências e da metafísica. 